\title{
A great grand-daddy of ice cores
}

Jerry F. McManus

\section{A record of Earth's climate over the past eight ice ages and their associated interglacial periods has been uncovered from a new ice core in Antarctica, almost doubling the age of previous ice-core records.}

$\mathrm{M}$ illennium after millennium, the snow falling on Greenland and Antarctica has built up deep ice sheets that are invaluable archives of past conditions on Earth. Antarctica has now yielded the longest ice-core record yet ${ }^{1}$, one that covers a staggering 740,000 years, with more to come. This accomplishment is the result of an effort by the EPICA consortium (European Project for Ice Coring in Antarctica). The group's report, by lead author Eric Wolff and colleagues, appears on page 623, with further comment on page 596.

A decade ago, ice cores from Greenland provided compelling evidence for the persistent climatic instability of the last glacial cycle $^{2}$, which reached back more than 100,000 years through the last ice age and into the previous interglacial. In the polar desert of Antarctica, however, slower snow accumulation means the ice archives can span longer intervals, and what is arguably the single best climate record in existence comes from Vostok, East Antarctica ${ }^{3}$. This goes back approximately 400,000 years, taking in four glacial cycles. Yet even this grand-daddy of ice cores falls frustratingly short of reaching several climatic milestones - for instance, the interval when the dominant behaviour of the ice ages shifted; the time of the largest deglacial transition; and the early portion of an interglacial interval that began shortly before 400,000 years ago and may be the best analogy to the current interglacial that began more than 10,000 years ago ${ }^{4}$.

Wolff and colleagues ${ }^{1}$ report the first results obtained by drilling a core from 3-km-thick ice at a site known as Dome C in East Antarctica. These results provide a spectacular record that extends back through eight glacial cycles (Fig. 1), confirming aspects of the Vostok record and providing a view of the preceding climatic milestones.

A large team is necessary in projects of this sort because of the demanding field operations, and also because of the many analytical approaches needed to extract information from the ice. For example, measurements of the physical characteristics of the atmosphere over the ice sheet (such as its temperature and dustiness recorded in snow and eventually ice) may be directly compared with data about the composition of the atmosphere itself (recorded in the air bubbles trapped as snow turns to ice). Such comparisons have established the connection

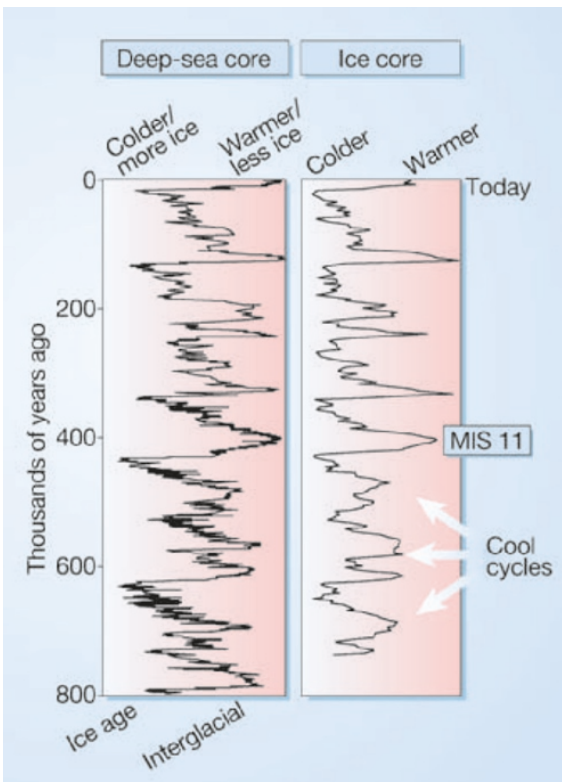

Figure 1 Glacial cycles of the past 800,000 years. The history of deep-ocean temperatures and global ice volume is inferred from a highresolution record of oxygen-isotope ratios measured in bottom-dwelling foraminifera shells preserved as microfossils in Atlantic Ocean sediments ${ }^{6,10,11}$. Air temperatures over Antarctica are inferred from the ratio of deuterium and hydrogen in the ice at Dome C (ref. 1). Marine Isotope Stage 11 (MIS 11) is an interglacial that bears some similarity to the most recent warm period $^{4}$, yet lasted many thousands of years longer. Note the smaller magnitude and less-pronounced interglacial warmth of the glacial cycles that preceded MIS 11.

between changes in atmospheric concentrations of carbon dioxide and temperature during the past few glacial cycles, and a similar connection between increased dust deposition and glacial periods that are thus inferred to be arid and/or windy.

The Dome $\mathrm{C}$ record includes dust concentrations and temperature estimates based on the deuterium to hydrogen ratio in the ice. Further work will increase the resolution of these data, and extend them to the base of the ice, perhaps reaching back another 200,000 years. Greenhouse-gas data have been generated for the crucial interval around 400,000 years ago, and these will also be extended back in time.

Ice cores are not the only source of climate records. They are complemented by data from terrestrial settings and from deep-sea sediments, which are especially useful because they provide better spatial coverage of the Earth and may extend much farther back in time. Both deep-sea and ice cores provide evidence for local temperature changes, ice cores additionally providing indications of atmospheric composition through the trapped air bubbles. Sediment cores contain the global signature of each glaciation, as recorded in the oxygen-isotope ratio of buried microfossil shells. This signature in part reflects temperature changes and in part the amounts of water residing in the isotopically very different reservoirs for water on Earth's surface - ice and ocean. It constitutes the basis for the scheme of marine isotope stages (MIS) for numbering glacial cycles, which counts the alternating ice ages and interglacials back in time, beginning with the present interglacial, MIS 1.

An intriguing aspect of long-term climate, revealed by deep-sea cores, is a shift in the pattern of glacial cycles that occurred without changes in the varying seasonal distribution of sunlight that is believed to pace the ice ages. Before one million years ago, glaciations of moderate extent waxed and waned in concert with 40,000-year variations in the tilt of Earth's rotation axis. During the past half-million years, the dominant period of these cycles is more like 100,000 years, similar to variations in the shape of Earth's elliptical orbit. So a transition in Earth's climatic response must have occurred as it entered this ' $100 \mathrm{~K}$ world'. These longer climate cycles have also been the largest in magnitude of all the ice-age cycles, combining with a long-term climatic trend towards more glacial conditions over millions of years to produce several of the most extreme glaciations on record (the last glacial maximum of the last ice age, MIS 2, for instance). Remarkably, the $100 \mathrm{~K}$ cycles have also resulted in the four mildest interglacial intervals of the past million years including MIS 1, which has, of course, seen the advent of human civilizations.

The new record ${ }^{1}$ provides further information about this transition, with the promise of more to come. Before 450,000 years ago, the glacial cycles display smaller amplitudes. Interestingly, the glacial portion of each cycle evinces nearly the same amount of cooling as during the more recent ice ages, whereas the warmer portion of each earlier 
cycle is clearly less pronounced. Wolff and colleagues also note that although the older cycles do not achieve nearly the same degree of warmth as subsequently, the warm intervals represent a much greater portion of the total cycle than was the case for the past few peak interglacial times; these seem to be increasingly brief, albeit pronounced, respites from the more typical harsh, unstable climate of the $100 \mathrm{~K}$ world 5 .

The EPICA team's recovery of undisturbed ice representing all of MIS 11 is of especial note. When this interglacial occurred, some 400,000 years ago, the slowly varying shape of Earth's elliptical orbit around the Sun was nearly circular. In this configuration, variations in the seasonal distribution of sunlight are due primarily to the tilt of Earth's axis, with little influence of the precession of the seasons around the orbit every 20,000 years. Because the Sun occupies a position that is nearer to one end of the ellipse, this precession results in the gradual cooling of northern summers over 10,000 years, as they migrate towards the more distant end of the orbit, culminating in conditions that are most conducive to year-round snow cover and the initiation of an ice age. A similar orbital configuration to that for MIS 11 holds today, and will for some time, making this interglacial a potential analogue for the natural development of Earth's climate in the future ${ }^{4}$. Northern Hemisphere summer now occurs when the Earth is near its farthest point from the Sun, although the nearly circular orbit raises the question of whether the resulting weak decline in northern summer insolation of today was sufficient to trigger the onset of an ice age in the past ${ }^{6}$.

Wolff et al. confirm that concentrations of the greenhouse gases $\mathrm{CO}_{2}$ and $\mathrm{CH}_{4}$ were also similar to pre-industrial levels during MIS 11, showing that the overall controls on incoming and outgoing radiation that drive climate were similar. Their deuterium and dust records indicate that the magnitude of the climatic response was likewise similar, and the 28,000 years of relative warmth in Antarctica is in keeping with evidence for prolonged warmth elsewhere ${ }^{6-10}$. This suggests that Earth's climate may have 'skipped a beat' when its orbit was nearly circular $^{6}$, rather than returning to an ice age after the 10,000 years of one half-precession cycle. The new results are perhaps the best evidence yet that MIS 11 was akin to the current interglacial - except, of course, that we now have rising concentrations of $\mathrm{CO}_{2}$ and have yet to see if 'our' interglacial might last another 20,000 years.

A priority for further investigations will be completing the gas records from air trapped in the Dome C ice. Given the complete record, it may be possible to detect an overall decline in greenhouse gases that might help to account for the long-term deterioration of global climate. Equally important is the question of whether the earlier warm intervals were associated with lower greenhouse-gas concentrations than have been achieved within the past few cycles. Such evidence will help us to find out whether the accentuated warmth of peak interglacial intervals within the $100 \mathrm{~K}$ world was associated with 'elevated' atmospheric greenhouse-gas levels that have been increasingly surpassed in the post-industrial era.

Jerry F. McManus is in the Department of Geology and Geophysics, 121 Clark Laboratory, Woods Hole Oceanographic Institution, Woods Hole,

Massachusetts 02543, USA.

e-mail: jmcmanus@whoi.edu

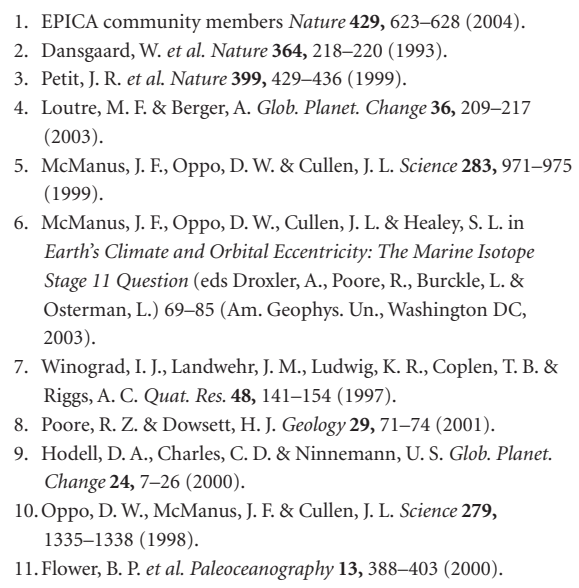

1. EPICA community members Nature 429, 623-628 (2004).

2. Dansgaard, W. et al. Nature 364, 218-220 (1993).

3. Petit, J. R. et al. Nature 399, 429-436 (1999).

4. Loutre, M. F. \& Berger, A. Glob. Planet. Change 36, 209-217 (2003).

5. McManus, J. F., Oppo, D. W. \& Cullen, J. L. Science 283, 971-975 (1999).

6. McManus, J. F., Oppo, D. W., Cullen, J. L. \& Healey, S. L. in Earth's Climate and Orbital Eccentricity: The Marine Isotope Stage 11 Question (eds Droxler, A., Poore, R., Burckle, L. \& Osterman, L.) 69-85 (Am. Geophys. Un., Washington DC, 2003).

7. Winograd, I. J., Landwehr, J. M., Ludwig, K. R., Coplen, T. B. \& Riggs, A. C. Quat. Res. 48, 141-154 (1997).

8. Poore, R. Z. \& Dowsett, H. J. Geology 29, 71-74 (2001).

9. Hodell, D. A., Charles, C. D. \& Ninnemann, U. S. Glob. Planet. Change 24, 7-26 (2000).

10. Oppo, D. W., McManus, J. F. \& Cullen, J. L. Science 279, 1335-1338 (1998)

11. Flower, B. P. et al. Paleoceanography 13, 388-403 (2000).

Animal behaviour

\section{Eavesdropping on bats}

\section{Brock Fenton and John Ratcliffe}

Two investigations into bat echolocation provide striking examples of the sophistication and the possible evolutionary and ecological consequences of variability in call design.

\section{n 1794, Lazzaro Spallanzani reported} experimental results supporting his earlier proposal that bats could 'see' with their ears. The famed Georges Cuvier found the suggestion preposterous ${ }^{1}$, however, and it took almost another 150 years for Spallanzani to be vindicated. After repeating many of Spallanzani's experiments, Donald Griffin ${ }^{2}$ published the same conclusions in 1940, coining the term 'echolocation' to describe how bats use echoes of the sounds they produce to locate objects in their path. A microphone sensitive to sound frequencies above the range of human hearing, a bat detector, allowed Griffin to eavesdrop on what bats said as they flew through an obstacle course in the dark.

Today, we know that there is variation between bat species in the design of echolocation calls, which often coincides with differences in their behaviour and ecology $y^{3}$. Two papers in this issue, by Kingston and Rossiter $^{4}$ and Siemers and Schnitzler ${ }^{5}$, advance this line of investigation further.

Kingston and Rossiter (page 654) ( $^{4}$ examined the situation in a single species, the large-eared horseshoe bat (Rhinolophus philippinensis), which occurs from southeast Asia to Australia. They showed how echolocation signals can diverge within a species and how this divergence might promote sympatric speciation - the division of one species into two or more without a geographical barrier. This is a hot and contentious topic in evolutionary biology. In three study areas, Kingston and Rossiter found three distinct variants of large-eared horseshoe bats differing in size, echolocation calls and relatedness. The largest was almost

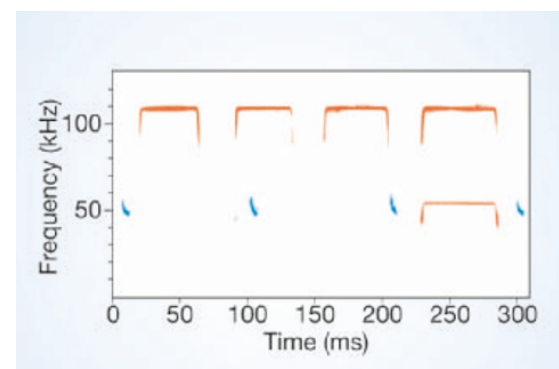

Figure 1 The two sides of the echolocation fence. These calls represent bats that separate pulse and echo in frequency (Rhinolophus, high-duty cycle, orange) and those separating them in time (Pipistrellus, low-duty cycle, blue). The high-duty calls are long, separated by short periods of silence and dominated by a single frequency; the low-duty calls are short, separated by long periods of silence and are not dominated by a single frequency. The fourth call of the Rhinolophus includes a lower-frequency harmonic as discussed by Kingston and Rossiter ${ }^{4}$. The bats foraged along the edge of a watercourse south of the Dead Sea, and the recording — made by M. B. Fenton - is unusual because it captures both types of cycle simultaneously.

twice as heavy as the smallest, and the sounds dominating their echolocation calls ranged from $27.2 \pm 0.2 \mathrm{kHz}$ in the largest to $53.6 \pm 0.6 \mathrm{kHz}$ in the smallest.

The level of detail available to an echolocating bat is a function of the wavelength of the sounds in its echolocation calls, and so differences in the frequencies that dominate its calls influence a bat's auditory scene ${ }^{6}$. Bats using high frequencies (shorter wavelengths) can detect smaller prey than can 